\title{
Comparison between early Odin-SMR, Aura MLS and CloudSat retrievals of cloud ice mass in the upper tropical troposphere
}

\author{
P. Eriksson ${ }^{1}$, M. Ekström ${ }^{1}$, B. Rydberg ${ }^{1}$, D. L. Wu ${ }^{2}$, R. T. Austin ${ }^{3}$, and D. P. Murtagh ${ }^{1}$ \\ ${ }^{1}$ Department of Radio and Space Science, Chalmers University of Technology, Gothenburg, Sweden \\ ${ }^{2}$ Jet Propulsion Laboratory, California Institute of Technology, Pasadena, California, USA \\ ${ }^{3}$ Department of Atmospheric Science, Colorado State University, Fort Collins, Colorado, USA
}

Received: 17 July 2007 - Published in Atmos. Chem. Phys. Discuss.: 14 August 2007

Revised: 11 January 2008 - Accepted: 11 March 2008 - Published: 3 April 2008

\begin{abstract}
Emerging microwave satellite techniques are expected to provide improved global measurements of cloud ice mass. CloudSat, Aura MLS and Odin-SMR fall into this category and early cloud ice retrievals from these instruments are compared. The comparison follows the SMR retrieval product and is made for partial ice water columns above $12 \mathrm{~km}$. None of the retrievals shows a significant degree of false cloud detections, the ratio between local mean values from the instruments is fairly constant and a consistent view of the geographical distribution of cloud ice is obtained. However, important differences on the absolute levels exist, where the overall mean is $9.6,4.2$ and $3.7 \mathrm{~g} \mathrm{~m}^{-2}$ for CloudSat, SMR and MLS, respectively. Assumptions about the particle size distribution (PSD) are a consideration for all three instruments and constitute the dominating retrieval uncertainty for CloudSat. The mean for CloudSat when applying the same PSD as for MLS and SMR was estimated to $6.3 \mathrm{~g} \mathrm{~m}^{-2}$. A second main consideration for MLS and SMR are the effects caused by the poorer spatial resolution: a possible vertical misplacement of retrieved values and an impact of cloud inhomogeneities. The latter effect was found to be the dominating retrieval uncertainty for SMR, giving a possible mean value range of $2.3-8.9 \mathrm{~g} \mathrm{~m}^{-2}$. The comparison indicates a common retrieval accuracy in the order of $70 \%$. Already this number should suffice for improved validations of cloud ice parametrisation schemes in atmospheric models, but a substantially better consistency between the datasets should be attainable through an increased understanding of main retrieval error sources.
\end{abstract}

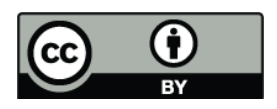

Correspondence to: P. Eriksson (patrick.eriksson@chalmers.se)

\section{Introduction}

The circulation of water through the atmosphere is key to the Earth's climate system, but this branch of the hydrological cycle is still not fully understood due to its complexity and measurement system limitations. Traditional satellite observation techniques largely fail at providing information on the internal structure of ice clouds and knowledge of the tropospheric cloud ice component is particularly poor. There is not even a consistent view upon such a basic variable as the vertically integrated cloud ice mass, often denoted as the ice water path (IWP). For example, the zonal mean IWP in climate models used in the 4th assessment of the Intergovernmental Panel on Climate Change differs with up to one order of magnitude, and the IWP response to increasing levels of $\mathrm{CO}_{2}$ deviates in sign (John and Soden, 2006).

Satellite techniques are needed to obtain the geographical and temporal coverage required for running and validating global atmospheric models. The climate is driven by fluxes of optical and IR radiation and satellite observations in these wavelength regions are important for understanding cloud radiative forcing. Morphological data, such as occurrence frequency and cloud top altitude are also obtained, but information on micro-physical properties is restricted to thinner clouds or the cloud top layer (e.g. Dessler and Yang, 2003). This is the case as cloud particles interact strongly with optical and IR radiation.

A comparison of possible measurement approaches must consider the cloud penetration capability, the strength of atmospheric gaseous absorption and that the measured signal should be generated by interaction with particles carrying a dominating fraction of the cloud ice mass. Such comparisons have found that $\mathrm{mm}$ and sub-mm technologies are the most suitable for characterising the bulk properties of thicker clouds (Evans and Stephens, 1995; Evans et al., 1998). The relative importance of observations at different wavelengths depends on the atmospheric conditions, the

Published by Copernicus Publications on behalf of the European Geosciences Union. 
technology selected (active or passive) and the observation geometry (down-looking or limb sounding). Cloud ice absorption is relatively low at $\mathrm{mm}$ and sub-mm wavelengths, and clouds affect the measured radiation mainly through scattering.

Present meteorological microwave satellite sensors, such as AMSU-B, all are down-looking and operate at frequencies below $190 \mathrm{GHz}$. Only the largest cloud ice particles cause significant scattering for these observing conditions, and data of AMSU-B type have primarily been used to identify deep convection at tropical latitudes (Hong et al., 2005). Limb sounding offers longer propagation paths through the atmosphere and this results in a sensitivity to a higher number of ice cloud types. Ice water content (IWC) retrievals based on $203 \mathrm{GHz}$ radiances were presented for UARS MLS (Wu et al., 2005), the first satellite microwave limb sounder launched in 1991.

The other two examples of satellite microwave limb sounders, Odin-SMR (Murtagh et al., 2002) and Aura MLS (Waters et al., 2006), are both in operation, and are also the only other examples of satellite observations in the frequency range above $200 \mathrm{GHz}$. Based on the good experience from UARS MLS, IWC retrievals were a design target of Aura MLS, and promising initial results involving validation of atmospheric models have already been presented ( $\mathrm{Li}$ et al., 2005, 2007; Su et al., 2006a,b). These results are based on observations at $240 \mathrm{GHz}$, but unofficial results from 115,190 and $640 \mathrm{GHz}$ also exist (Wu et al., 2006). The operational Odin-SMR processing covers strato- and mesospheric altitudes, but an off-line dual frequency $(501 / 544 \mathrm{GHz})$ retrieval approach for deriving humidity and a partial IWP product for the tropical upper troposphere has been presented recently (Ekström et al., 2007; Eriksson et al., 2007a). Similar comparisons with ECMWF and climate models in Li et al. (2005) and Eriksson et al. (2007a) indicate an overall agreement between Odin-SMR and Aura MLS cloud mass retrievals, while a first direct comparison of the datasets is presented here.

Active techniques provide cloud observations with much higher spatial resolution than the passive methods discussed above. Lidars, being an optical/IR method, are most suitable for thinner clouds. Radars require high frequency pulses or large antennas to obtain sensitivity to cloud ice particles. Two ground-based networks of such radars exist: ARM (www.arm.gov) and CloudNet (www.cloud-net.org). CloudSat, launched in 2006 and operating at $94 \mathrm{GHz}$, is the first space-borne radar of this type, and signifies a very important step forward in global remote sensing of clouds (Stephens et al., 2002). The first complete CloudSat ice mass retrieval product (2B-CWC-RO, release R04) has just been released ${ }^{1}$.

\footnotetext{
${ }^{1}$ Austin, R. T., Heymsfield, A. J., and Stephens, G. L.: Retrievals of ice cloud microphysical parameters using the CloudSat millimeter-wave radar and temperature, J. Geophys. Res., submitted, 2008.
}

It can then be expected that global measurements of cloud ice mass are now performed with improved accuracy, and by three different sensors. However, important retrieval uncertainties still exist and different validation efforts are needed. This paper contributes to these efforts by investigating the consistency between early versions of Odin-SMR, Aura MLS and CloudSat IWC/IWP retrievals. Special attention is put on Odin-SMR as this is the first comparison study of this dataset. Aura MLS and CloudSat are also compared in Wu et al. (2008), but then in a broader context and using the provisional CloudSat data product (2B-CWC-RO, release R03). Some aspects of the main retrieval uncertainties are also emphasised here.

A main consideration for all present satellite techniques is that assumptions about the particle size distribution must be made in order to retrieve cloud ice masses. This introduces a substantial retrieval uncertainty as the particle distribution changes with local atmospheric conditions (Heymsfield and McFarquhar, 2002) and no parametrisation of general validity exists. A second main retrieval error source for instruments with poorer spatial resolution, such as Odin-SMR and Aura MLS, is that the cloud ice is not homogeneously distributed over the antenna footprint. This problem increases with the degree of non-linearity between cloud ice mass and observed signal. Different values of cloud ice mass, averaged over the footprint, can then cause the same signal, depending on the spatial distribution (Davis et al., 2007). This is often denoted as the beam filling effect.

\section{Data}

This section describes the datasets involved in the intercomparison. The aim is to compare official cloud ice mass retrievals from three satellite microwave sensors presently in operation: Odin-SMR, Aura MLS and CloudSat. The comparison follows the characteristics of the Odin-SMR retrieval approach and the data are mainly analysed as partial ice water paths, defined by Fig. 1. A restriction to the tropical area (latitudes inside $\pm 30^{\circ}$ ) is imposed by the fact that Odin-SMR has only sensitivity to ice above about $12 \mathrm{~km}$.

\subsection{Odin-SMR}

\subsubsection{Observations}

The Odin satellite was launched in February 2001 into a $\sim 600 \mathrm{~km}$ quasi-polar sun-synchronous orbit, with ascending node around 18:00 h. The payload includes the first space-borne sensor for atmospheric sub-mm observations, Odin-SMR. This limb sounding instrument measures thermal emission at frequencies around $500 \mathrm{GHz}$. The atmospheric signal is recorded through a $1.1 \mathrm{~m}$ telescope, single-sideband heterodyne receivers and two auto-correlation spectrometers with $800 \mathrm{MHz}$ bandwidth. Further information is found in, for example, Murtagh et al. (2002) and Ekström et al. (2007). 
The observation time of Odin is timeshared, both between astronomy and atmospheric science objectives, and between different atmospheric observation modes. The cloud ice retrievals are based on radiances from the stratospheric mode. These measurements are made approximately every third day. The data set includes $2.4 \times 10^{5}$ retrievals, covering the period 2001-07-24-2007-12-10, and can be obtained through www.rss.chalmers.se/ $\sim$ patrick/OdinUT.

\subsubsection{Retrieval approach}

Operational Odin-SMR processing does not account for cloud scattering and data are here taken from a separate retrieval algorithm providing relative humidities and cloud ice mass in the tropical upper troposphere. Ekström et al. (2007) and Eriksson et al. (2007a) provide a description of the algorithm and a detailed error characterisation, and only an overview of the retrieval approach is given here.

The retrieval considers only spectra from tangent altitudes below $9 \mathrm{~km}$, where the atmosphere around the tangent point acts as blackbody background to cloud scattering at higher altitudes. Clouds are then detected as a depression of the recorded brightness temperatures, $\Delta \mathrm{T}_{\mathrm{b}}$. The measurement strategy has therefore more of down-looking character and the footprint size is relatively small, compared to pure limb sounding geometry. The sampled volume is a tilted cylinder, where the horizontal cross-section has an area of about $2 \times 45 \mathrm{~km}^{2}$.

The observation geometry selected provides no inherent altitude information, but this problem is partly overcome by combining data from 501 and $544 \mathrm{GHz}$. This procedure results in the retrieval of a partial IWP, with an estimated response to cloud ice at different altitudes shown in Fig. 1. This retrieval product is below denoted as pIWP.

The mapping from derived $\Delta \mathrm{T}_{\mathrm{b}}$ values to pIWP relies on the particle size distribution of McFarquhar and Heymsfield (1997, hereinafter MH97) and radiative transfer calculations made for completely homogeneous cloud layers (1-D). The simple correction for cloud inhomogeneity suggested in Eriksson et al. (2007a) has been applied.

\subsection{Aura MLS}

\subsubsection{Observations}

Aura MLS is a passive instrument consisting of seven radiometers at frequencies near 118, 190, 240,640 GHz, and $2.5 \mathrm{THz}$ (Waters et al., 2006). The $118 \mathrm{GHz}$ and $2.5 \mathrm{THz}$ radiometers have two receivers at orthogonal polarisations. The $118 \mathrm{GHz}$ receivers are single-sideband, while at other frequencies double-sideband systems are employed. The Aura satellite has a 13:40 ascending node sun-synchronous orbit at $705 \mathrm{~km}$ altitude with $98^{\circ}$ inclination. The MLS on Aura views forwards in the satellite flying direction with daily latitude coverage from $82^{\circ} \mathrm{S}$ to $82^{\circ} \mathrm{N}$. The field of view

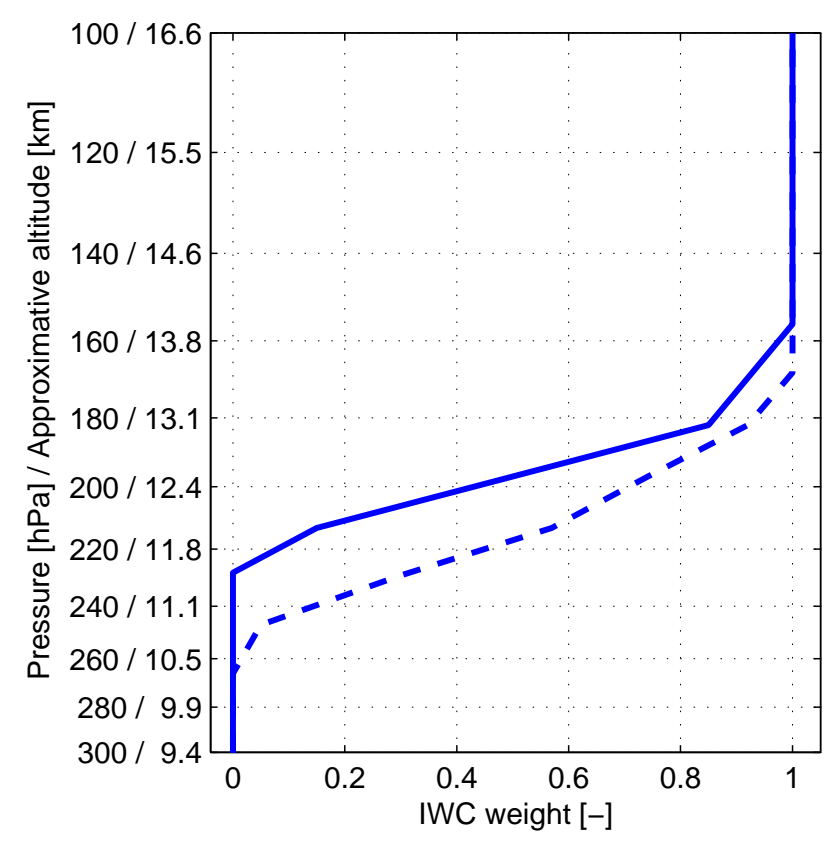

Fig. 1. Estimated average vertical response of considered OdinSMR retrievals (solid). Profiles of IWC are converted to SMR partial IWP (pIWP) by weighting with the function shown, often denoted as the averaging kernel. An alternative estimate of the response, is also included (dashed), to indicate the maximum uncertainty of the estimated response. Solid/dashed line is evaluated for $\Delta \mathrm{T}_{\mathrm{b}}=50 / 20 \mathrm{~K}$.

at $240 \mathrm{GHz}$ has a vertical size of $\approx 3.2 \mathrm{~km}$, and is $\approx 7 \mathrm{~km}$ in the cross-track dimension. MLS scans are synchronised to the orbital period such that nominal operation will have 240 limb scans per orbit. The data integration time for each measurement is $1 / 6 \mathrm{~s}$. For $\mathrm{GHz}$ measurements, each scan includes 40-50 spectra dedicated to tropospheric measurements with a $300 \mathrm{~m}$ sampling resolution in tangent height (Jarnot et al., 2006).

The second official Aura MLS data product is denoted as version 2.2 and is used here. MLS data were extracted to match as closely as possible the selected CloudSat data (see below). All MLS data from the CloudSat time period (060701-070630) were included, but as the backward V2.2 processing of MLS data is not complete data from other years had to be included to obtain 365 days of data $\left(4.3 \times 10^{5}\right.$ profiles). Data from other years were selected according to best match in "day of the year".

\subsubsection{Retrieval approach}

The V2.2 IWC data product is based on measurements around $240 \mathrm{GHz}$ and covers altitudes in the range 261$68 \mathrm{hPa}$. The officially suggested screening and bias correction of data (Wu et al., 2006) has been performed.

The fundamental quantity for Aura MLS cloud ice retrievals is the difference between measured and expected 
clear-sky radiance, named as the cloud-induced radiance $\mathrm{T}_{\text {cir. }}$. This is basically the same quantity as the Odin-SMR $\Delta T_{b}$, but there are some important practical differences. First of all, $\mathrm{T}_{\text {cir }}$ is determined as part of the operational processing, where the estimation of clear-sky radiance incorporates retrieval information from other bands and $\mathrm{T}_{\text {cir }}$ should be more accurately determined than $\Delta \mathrm{T}_{\mathrm{b}}$. Further, the Aura MLS retrievals are made at higher tangent altitudes, and at a frequency with comparably low optical thicknesses. This causes relevant $T_{\text {cir }}$ values to be strictly positive.

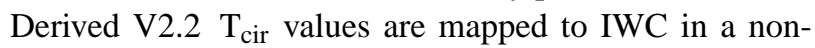
linear manner, as described in Wu et al. (2006). This is an important improvement compared to the earlier V1.5 version where a linear mapping was applied. The sensitivity is degraded with increasing $T_{\text {cir }}$ and saturation is reached for IWC $\approx 0.1 \mathrm{~g} \mathrm{~m}^{-3}$. This causes an underestimation for MLS retrievals in the cases where IWC $>0.1 \mathrm{~g} \mathrm{~m}^{-3}$. The MLS IWC retrievals assume the MH97 PSD, as for Odin-SMR.

\subsection{CloudSat}

\subsubsection{Observations}

CloudSat is a satellite mission designed to measure the vertical structure of clouds from space (Stephens et al., 2002). The satellite flies in tandem with Aura, and has accordingly the same orbit properties. CloudSat carries a $94 \mathrm{GHz} 0.16^{\circ}$ off-nadir looking radar which measures the power backscattered by clouds as a function of distance from the radar. The standard data product consists of 125 vertical bins that are $240 \mathrm{~m}$ thick, while the vertical resolution of the radar is approximately $500 \mathrm{~m}$. Each profile is generated over a $160 \mathrm{~ms}$ integration, with a 6-dB footprint resolution of approximately $1.3 \mathrm{~km}$ across-track and $1.7 \mathrm{~km}$ along-track. The minimum detectable equivalent radar reflectivity is approximately $-30 \mathrm{dBZ}$ and the dynamic range is $70 \mathrm{dBZ}$. This study focuses on the first official product with complete time coverage, denoted as release 4 (R04), but the quality of the provisional release 3 (R03) is also commented.

IWC profiles from the 2B-CWC-RO R04 product for the period of 2006-07-01-2007-06-30 are considered. This time period provides $6.1 \times 10^{7}$ profiles inside the considered latitude range. The profiles are mapped to pIWP and these column values are averaged in a first step to achieve a $10 \mathrm{~km}$ along track resolution. The data are later averaged further to match the different footprint size of Odin-SMR and Aura MLS. Public available R03 data exist for the period of 15 October-15 November 2006, while R04 data exist for the entire mission to date (with a slight delay for the most recent observations).

\subsubsection{Retrieval approach}

The CloudSat 2B-CWC-RO R04 IWC product is retrieved from radar reflectivity measurements alone, but temperature profiles from ECMWF model runs are used as auxiliary inputs affecting the a priori values ${ }^{1}$. In the R04 retrieval algorithm, a log-normal particle size distribution is assumed. (The R03 algorithm used a gamma particle size distribution.) Such a function can be completely characterised by three parameters: the width and geometric mean diameter of the distribution and the total number concentration of particles. Profiles of the distribution width, number concentration, and geometric mean diameter values are retrieved in an optimal estimation framework that uses a priori size distribution values based on parametrisations that depend on temperature and the reflectivity level. (The R03 algorithm retrieved single values for the column distribution width and number concentration rather than profiles of these quantities.) The IWC can then be estimated based on the retrieved particle size distribution parameters. The retrieval approximates ice particles as spheres and applies a correction for Mie scattering.

\section{Results and discussion}

\subsection{Particle size sampling}

The interaction between radiation at a given wavelength and a cloud ice particle depends on the particle's size, shape and complex refractive index. The overall radiative impact of cloud ice inside a given volume depends further on the particle size distribution (PSD). These facts cause a remote sensing system to have a maximum sensitivity to a specific particle size range. If the purpose of the measurement is to estimate IWC or IWP, it is of course beneficial if the range of maximum sensitivity corresponds to particles carrying a large fraction of the ice mass.

This aspect is investigated by Fig. 2, for the satellite observations considered and a characteristic infrared wavelength. Two cases are selected to represent a high cloud $(\approx 15 \mathrm{~km})$ around the lower detection limit of the microwave techniques and a typical cloud around $12 \mathrm{~km}$. Different cross-section components are considered, to best represent the properties of each measurement technique. The secondary maximum in MLS sensitivity functions around $50 \mu \mathrm{m}$ corresponds to particle absorption, as shown by Fig. A1 in Wu et al. (2005). Absorption is neglected for Odin-SMR due to the different observation geometry applied. In short, absorption gives a low radiative effect as absorbed energy is replaced with emission of similar strength, as described in Eriksson et al. (2007a).

Figure 2 confirms that IR radiation interacts primarily with smaller particles, while the microwave techniques are more sensitive to larger particles. The IR response is highest up to $\sim 100 \mu \mathrm{m}$. For the "thin cloud" case, the range of high response ( $>0.5$ ) for the IR wavelength corresponds roughly to the lower half of the mass, while the microwave responses (MLS is discussed separately below) match approximately the upper third. The situation is reversed for the "thick cloud": $30 / 50 \%$ coverage but with the highest value for 

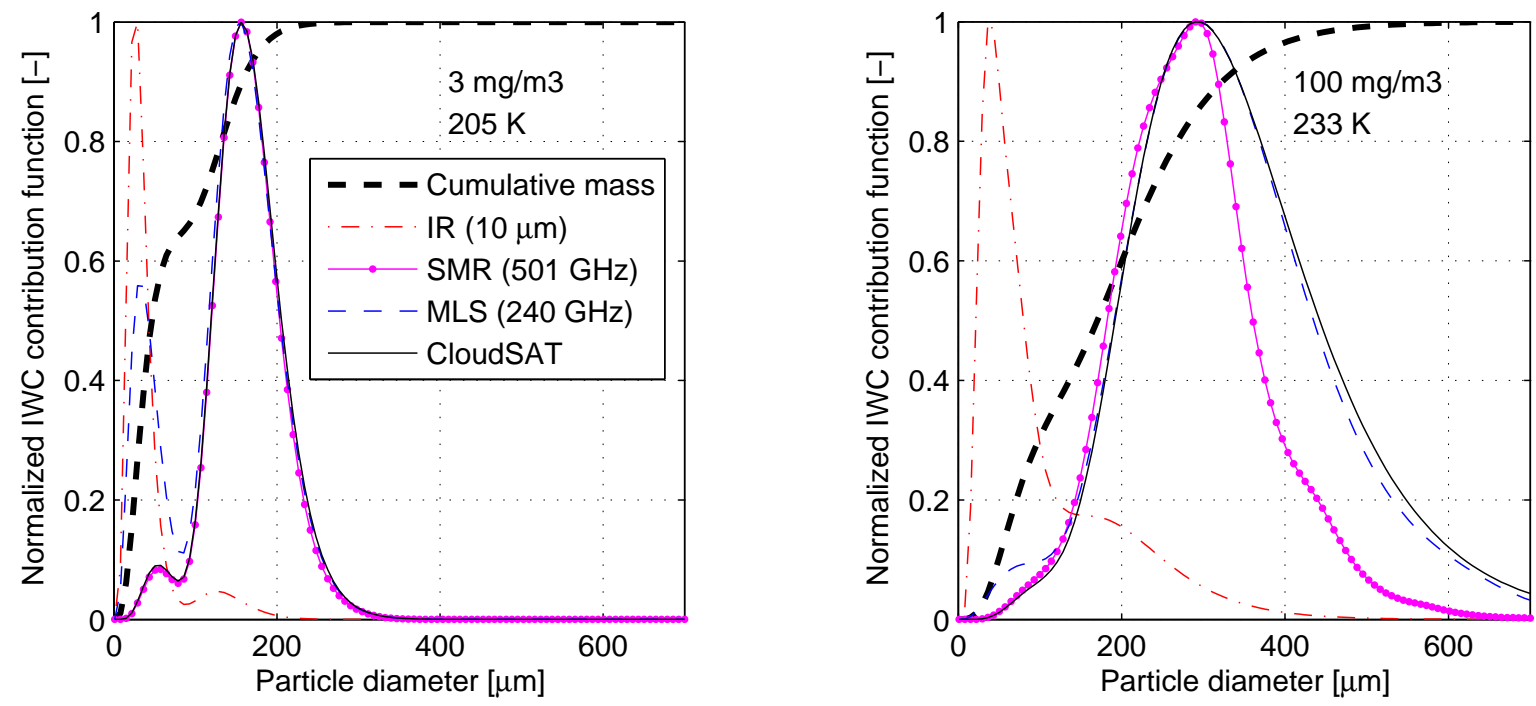

Fig. 2. Estimates of relative sensitivity to different particle sizes for some remote sensing instruments. Two combinations of IWC and temperature are shown: $3 \mathrm{mg} \mathrm{m}^{-3}$ at $205 \mathrm{~K}$ (left) and $100 \mathrm{mg} \mathrm{m}^{-3}$ at $233 \mathrm{~K}$ (right). Spherical particles and the MH97 PSD are assumed. Cumulative mass distributions are shown as dashed lines. The instrument responses are estimated as the product between PSD and the sizedependent cross-section. The complete extinction cross-section is considered for IR and MLS, only the scattering cross-section for SMR, and the backscattering cross-section for CloudSat. All functions are normalised with their maximum value. The figure shall only be interpreted in a schematic manner as no complete radiative transfer calculations are involved.

microwaves. However, this discussion assumes that MH97 is a valid approximation of the PSD, and distinctly different relative responses are likely found at particular atmospheric conditions.

An interesting exception to the discussion above is MLS and the "thin cloud" case, where the response function shows a clear sensitivity to both small and large particles, caused by a combined effect of absorption and scattering. More detailed simulations would show an even higher relative response to small particles as extinction due to absorption here influences the measured spectra more strongly. MLS is in this aspect the most suitable choice among the microwave instruments for measuring the ice mass in thinner clouds, on the condition that a detectable signal is obtained.

The scattering for MLS and CloudSat is predominately of Rayleigh character. That is, the scattering strength is proportional to $D^{6}$, where $D$ is the particle diameter. The relatively shorter wavelength of SMR results in a transition to Mie conditions at a smaller particle size, and this gives a lower relative response for particles above $\sim 300 \mu \mathrm{m}$. The consequence is that MLS and CloudSat retrievals are more easily affected by large particles above the PSD range important for the total mass, than SMR. A potential for discriminating between medium sized and large particles by combining $\mathrm{mm}$ and sub$\mathrm{mm}$ receivers has also been shown (e.g. Buehler et al., 2007).

A high variety of local size distributions can be found for identical combinations of e.g. IWC and temperature, and it is clear that a PSD parametrisation of general validity can not be found. The difference between actual and local mean
PSDs will cause a random retrieval error, while a deviation between local mean and assumed PSD will be mapped to a systematic IWC error. The latter is of greatest concern here since only mean values are considered. Retrievals based on microwave observations will underestimate the IWC if the assumed PSD contains too high a fraction of large particles, while too low a fraction of large particles gives an overestimation. The tendency for IR measurements is the reverse.

Several uncertainties concerning average PSD in the atmospheric region of interest exist. The number of in-situ measurements is limited, especially for temperatures below $-50^{\circ} \mathrm{C}$, and there are clear discrepancies between data from different in-situ measurement techniques. For example, it has been suggested that some probes cause shattering of larger particles (Heymsfield, 2007). If this hypothesis were correct and such PSDs are used for these retrievals, the result should be an overestimation of IWC. However, an underestimation of IWC is also possible as other measurement data indicate that high altitude ice particles at low latitudes are smaller than generally assumed (Garrett et al., 2003).

Alternative PSD assumptions have been tested for both SMR and MLS. The PSD of Donovan (2003) was considered in Eriksson et al. (2007a) and the difference compared to applying MH97 was found to be around $-25 \%$ at $-40^{\circ} \mathrm{C}$ and increasing to $>100 \%$ at $-60^{\circ} \mathrm{C}$. The systematic retrieval uncertainty for pIWP was estimated as $40 \%$ based on these values. In Wu et al. (2008) different modifications of MH97 and three other PSDs were analysed to estimate the PSD related error for MLS. Modifications of MH97 resulted in 

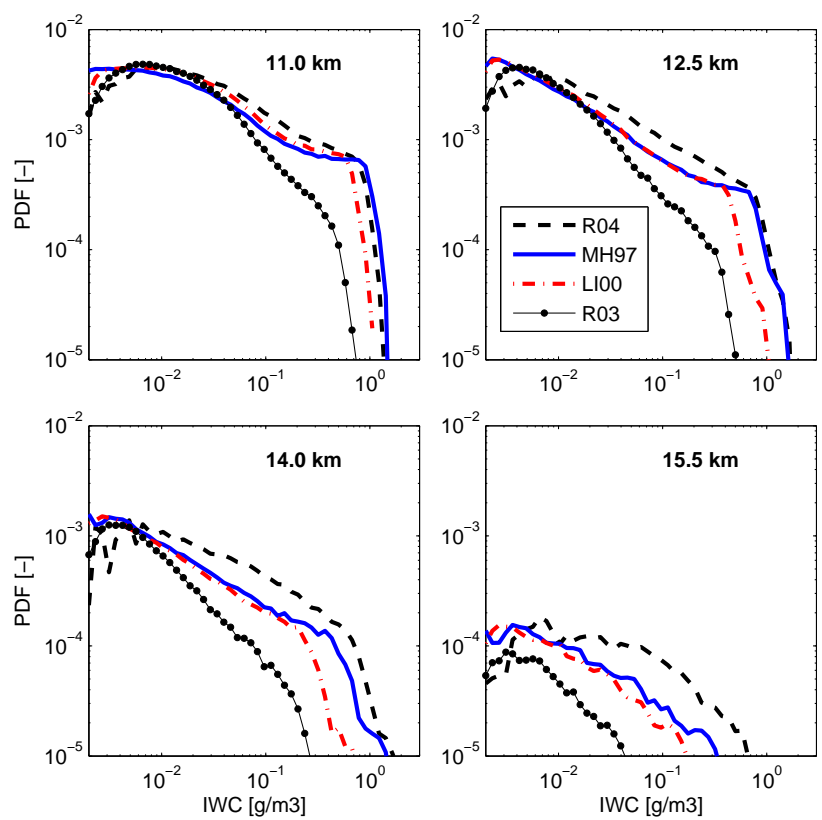

Fig. 3. Probability density functions of retrieved IWC values for official CloudSat R03 and R04 data, following LI00 and a methodology based on MH97. All the data are from the period 15 October15 November 2006. The R04, LI00 and MH97 results are for an identical dataset, including all tropical data from the time period considered except profiles with some dBZ or R04-IWC error flag. The same filtering was performed for R03, but using the retrieval diagnostics of that release which result in a somewhat smaller dataset.

differences mostly below $40 \%$, while a switch to any of the other PSDs gave varying results, with some changes exceeding $100 \%$.

The official CloudSat data products are compared to some alternative retrievals in Fig. 3 and Table 1. This comparison can be taken as an investigation of the PSD sensitivity of CloudSat retrievals, though an explicit PSD is only found in one of the cases. This case is a retrieval methodology based on MH97. These retrievals were achieved by calculating PSD integrated Mie backscattering cross-sections for the CloudSat frequency and a set of temperatures. In this way a look-up table for mapping individual $\mathrm{dBZ}$ values to IWC was created. The method of Liu and Illingworth (2000, hereinafter LI00) operates also on individual dBZ values, where the mapping function has been derived directly from in-situ data, and the assumed PSD is only implicitly defined by the derived dBZ-IWC relationship. No fixed PSD can be specified for the CloudSat retrievals. A particular functional form is selected (gamma and log-normal for R03 and R04, respectively), but new parameter values are derived for each measurement. Accordingly, there exists no particular PSD for a given IWC, as for MH97 and LI00. The retrievals are further performed on profile basis, and the PSD derived for one altitude depends on data from other altitudes. The fact that no explicit PSD exists for LI00, R03 and R04 has the con-
Table 1. Mean results for results displayed in Fig. 3.

\begin{tabular}{lccccc}
\hline Retrieval & & \multicolumn{4}{c}{ Retrieval method } \\
quantity & Unit & R04 & LI00 & MH97 & R03 \\
\hline IWC @ $11.0 \mathrm{~km}$ & $\mathrm{mg} \mathrm{m}^{-3}$ & 7.32 & 5.61 & 6.59 & 2.49 \\
IWC @ $12.5 \mathrm{~km}$ & $\mathrm{mg} \mathrm{m}^{-3}$ & 4.36 & 2.37 & 3.28 & 1.11 \\
IWC @ $14.0 \mathrm{~km}$ & $\mathrm{mg} \mathrm{m}^{-3}$ & 1.60 & 0.57 & 0.94 & 0.23 \\
IWC @ 15.5 km & $\mathrm{mg} \mathrm{m}^{-3}$ & 0.22 & 0.05 & 0.09 & 0.01 \\
pIWP & $\mathrm{g} \mathrm{m}^{-2}$ & 6.29 & 2.76 & 4.13 & 1.21 \\
\hline
\end{tabular}

sequence that corresponding retrievals can not be performed for SMR and MLS.

There is a consistent pattern among the CloudSat retrievals and for all four altitudes considered; the lowest values are obtained by LI00, while the official R04 data provide the highest estimates. This is valid for both PDFs above $0.01 \mathrm{~g} \mathrm{~m}^{-3}$ (Fig. 3) and mean values (Table 1). The difference increases with increasing altitude (or decreasing temperature), which is in accordance with the discussion above that more uncertainties exist around the average PSD at higher altitudes. The MH97 retrievals are between LI00 and R04, with the exception for the PDF for $11.0 \mathrm{~km}$. Mean pIWP for the three retrieval approaches can be summarised as $4.52 \pm 1.77 \mathrm{~g} \mathrm{~m}^{-2}$. This corresponds to a relative accuracy of $39 \%$.

\subsection{Impact of cloud inhomogeneity}

Cloud ice fields normally show horizontal inhomogeneities over distances corresponding to the footprint sizes of Aura MLS and Odin-SMR. This causes a beam filling effect (see the introduction) as the relationship between cloud ice amount and measured signal is non-linear (see Fig. 6 in Wu et al. (2006) for MLS and Fig. 6 in Eriksson et al. (2007a) for SMR). The relationship of concern is approximately linear up to $20 \mathrm{~g} \mathrm{~m}^{-2}$ for SMR, while the same applies for MLS up to $\approx 30 \mathrm{mg} \mathrm{m}^{-3}$ (Wu et al., 2008). Assuming an effective cloud thickness of $2 \mathrm{~km}$ for higher pIWP, this indicates a larger linear regime of MLS with a factor of around 3, which is advantageous with respect to beam filling.

Improvements with respect to the beam filling issue are on-going for both SMR and MLS. For example, the next version of Odin-SMR retrievals will follow Evans et al. (2002) where the inversion database will be generated by performing 3-D radiative transfer calculations for cloud scenarios created from CloudSat backscatter data. The negative impact of cloud inhomogeneities is not avoided, but the effect will automatically be considered in both retrieved results and associated error estimates. A similar, but much simpler, approach is applied here to investigate the validity of the cloud inhomogeneity correction scheme for SMR suggested in Eriksson et al. (2007a). No CloudSat data were at hand at that moment and the suggestion was based on simple arguments around 
the pIWP $-\Delta \mathrm{T}_{\mathrm{b}}$ relationship and data from a case study made by Davis et al. (2007).

The results of the simplified characterisation are shown in Fig. 4. Synthetic Odin-SMR data were generated by mapping time series of CloudSat pIWP to $\Delta \mathrm{T}_{\mathrm{b}}$, and taking averages over $45 \mathrm{~km}$ (the along-track size of the SMR footprint). The mapping from pIWP to $\Delta \mathrm{T}_{\mathrm{b}}$, denoted as $f$ in the figure axes labels, was taken from the retrieval look-up tables. The antenna response is denoted as $r$. Simulated SMR measurements are obtained as $r(f(\mathrm{pIWP}))$. The retrieval assumes that pIWP averaged over the antenna footprint gives same $\Delta \mathrm{T}_{\mathrm{b}}$. The later quantity is $f(r$ (pIWP)).

Completely homogeneous ice fields are found at the diagonal of Fig. 4, while two different non-linear effects place inhomogeneous cases off the diagonal. Data points above the diagonal, only found for low $\Delta \mathrm{T}_{\mathrm{b}}$, are caused by a nonlinearity originating in the PSD. This effect was not foreseen by Eriksson et al. (2007a). The pIWP to $\Delta \mathrm{T}_{\mathrm{b}}$ mapping is further non-linear due to radiative transfer effects, and this feature is the origin to data points below the diagonal and would, if neglected, cause a systematic underestimation of pIWP. These effects can not be compensated on a single measurement basis, and the only option is to apply a general correction with the aim to obtain correct mean values.

The correction suggested in Eriksson et al. (2007a, Eq. 1) is included in Fig. 4. Numerical tests showed a small impact on final results when trying to incorporate the discovered reversed effect for low pIWP, and no adjustment of the correction function was found necessary. It is clear that there would be systematic underestimation of the cloud ice mass in thicker clouds if the beam filling effect is neglected, but an optimisation of the correction term was not attempted. The characterisation performed is too simple for that purpose. A direct fit of the data points in Fig. 4 would neither improve the situation as an optimisation must include the non-linear relationship between $\Delta \mathrm{T}_{\mathrm{b}}$ and pIWP. The performed exercise is included only to demonstrate the beam filling effect and justify the application of a correction term. An improved treatment of beam filling is left for future work.

Accordingly, the $20 \%$ correction suggested (for $\Delta \mathrm{T}_{\mathrm{b}}$ above $20 \mathrm{~K}$ ) was accepted as it catches the general properties of simulated results. It should be noted that the size of this correction parameter is highly important. For example, the overall mean of the SMR retrievals is $1.97,2.72,4.24$ and $7.06 \mathrm{~g} \mathrm{~m}^{-2}$ for a maximum correction of $0,10,20$ and $30 \%$, respectively. In Eriksson et al. (2007a) the retrieval error due to cloud inhomogeneities was estimated to have a systematic and random component $(1 \sigma)$ of 30 and $40 \%$, respectively. Figure 4 indicates that the possible range for

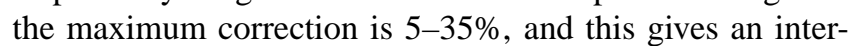
val of $2.3-8.9 \mathrm{~g} \mathrm{~m}^{-2}$ for the overall SMR mean. This would correspond to a $60 \%$ systematic retrieval uncertainty (only considering this error source) if the maximum correction was adjusted such that a symmetric error range was obtained

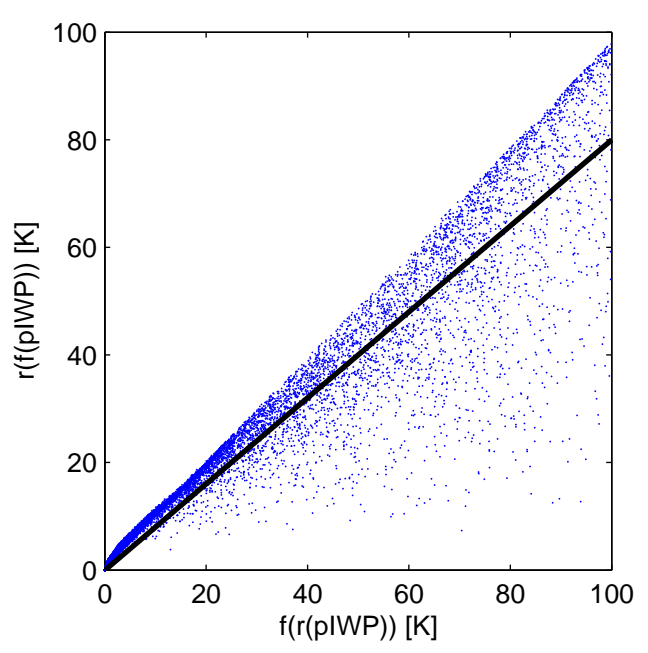

Fig. 4. Simple simulation of the beam filling effect for Odin-SMR. All available CloudSat data from January 2007 were considered, where 100000 randomly selected data points are displayed here. The horizontal data dimension represents the (1-D) retrieval assumptions made, while the vertical dimension aims at capturing real measurement conditions. The (black) line corresponds to the correction function suggested in Eriksson et al. (2007a). Further details are given in the text.

$\left(5.6 \pm 3.3 \mathrm{~g} \mathrm{~m}^{-2}\right)$, which then is in agreement with the earlier estimate.

\subsection{Geographical distributions}

The CloudSat, Aura MLS and Odin-SMR retrievals are displayed in Figs. 5-7 as annual and seasonal averages. The SMR fields are less smooth than the CloudSat and MLS ones, which can be expected due to a smaller statistical basis for the averaging. The important quantity for this difference is the atmospheric volume sampled by the measurements. The CloudSat and MLS datasets correspond both to complete coverage along the orbit over one year and similar atmospheric volumes are covered. The SMR dataset spans a longer time period, but the coverage is sporadic in both time or space, and the covered atmospheric volume is about a factor 7 lower.

The general structure of the cloud ice fields is consistent between the instruments, both with respect to annual averages and seasonal variations. In short, higher mean values are primarily found around the inter-tropical convergence zone (ITCZ), north-east parts of the Indian Ocean, western Pacific Ocean, central equatorial areas of Africa and South America. The south pacific convergence zone (SPCZ) can further be distinguished. The consistency between the fields is in fact high, even regarding finer details. For example, the strongest SPCZ, the least pronounced ITCZ for the eastern Pacific Ocean and highest mean value over Madagascar are found during the DJF season for all three instruments. 

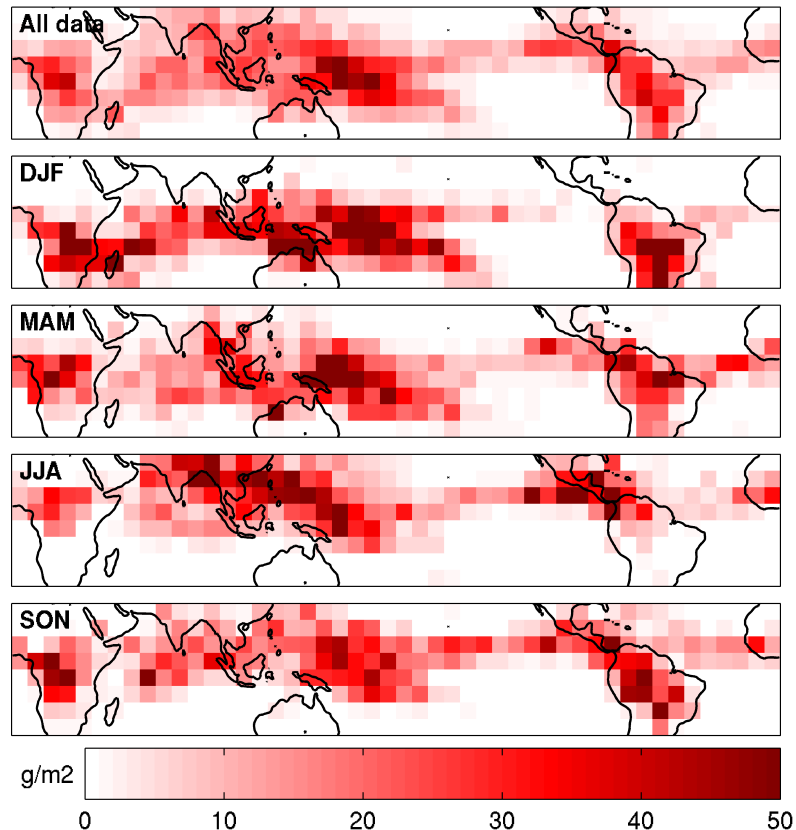

Fig. 5. Overall (top) and seasonal (lower four panels) mean pIWP fields for CloudSat. Data are averaged over $7.5^{\circ}$ in both latitude and longitude. Seasons are defined as: DJF $=$ Dec-Feb, MAM = Mar-May, JJA = Jun-Aug, and SON = Sep-Dec.
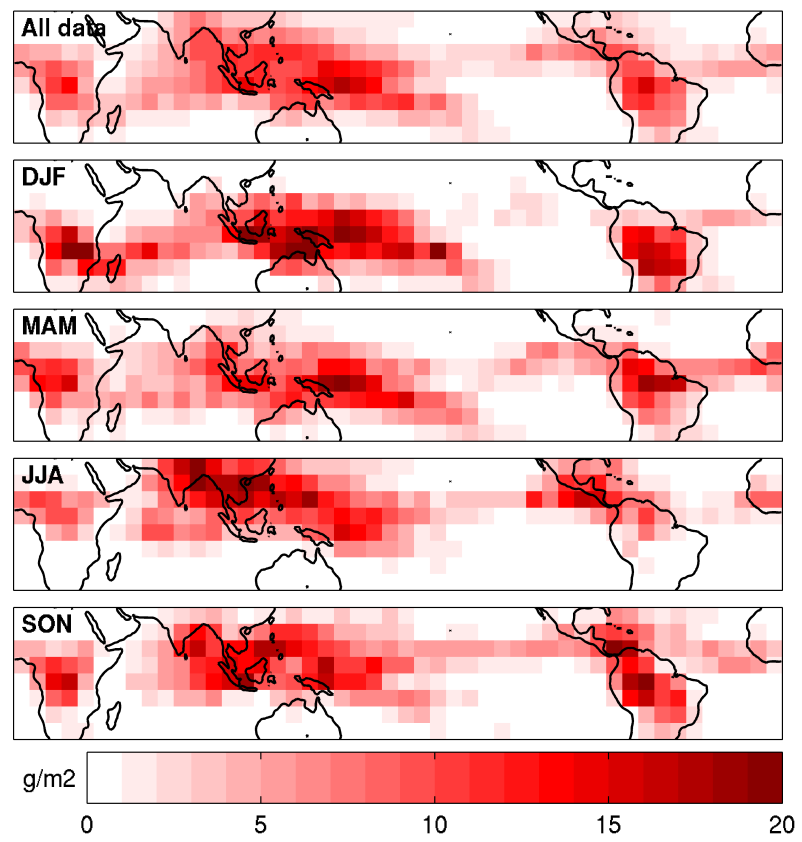

Fig. 6. Overall (top) and seasonal (lower four panels) mean pIWP fields for AURA MLS. Averaging and seasons as in Fig. 5, but the colour scale is here different.

A high stability of all three retrievals is also supported by the fact that there are large areas, common for the instruments, with mean pIWP below $1 \mathrm{~g} \mathrm{~m}^{-2}$. This shows that
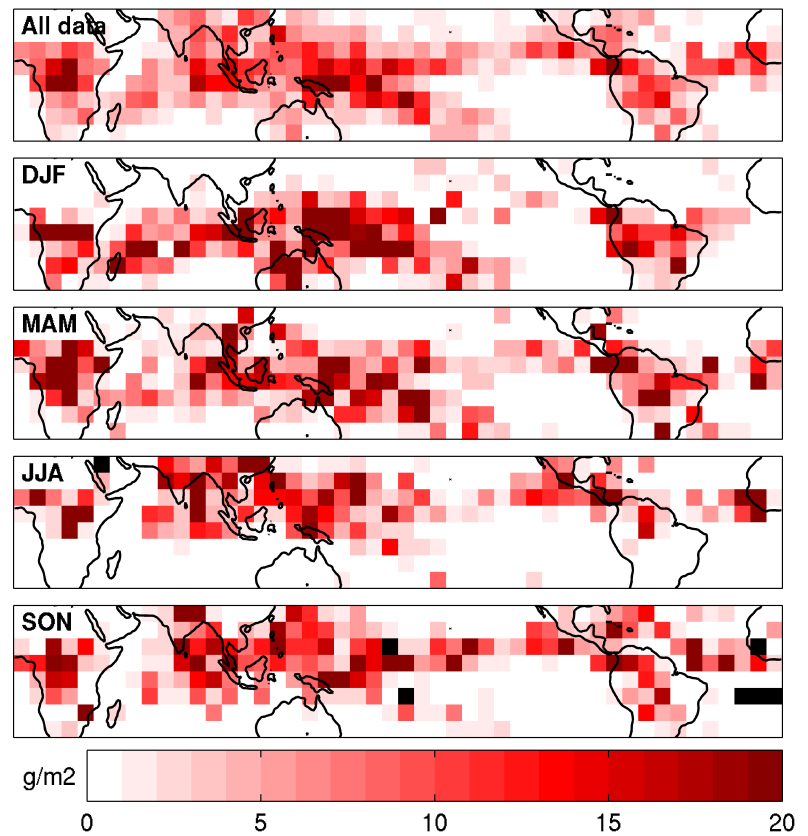

Fig. 7. Overall (top) and seasonal (lower four panels) mean pIWP fields for Odin-SMR. Averaging and seasons as in Fig. 5, and same colour scale as in Fig. 6. Black indicates less than 50 data points available for averaging and no IWP is given.

none of the instruments has a notable percentage of false cloud detections. However, some differences can be noted, such as a more pronounced southern end of the SPCZ and more cloud detections around and north of Hawaii for SMR, and to some extent also for MLS, compared to CloudSat. This could be an indication on a higher sensitivity of SMR and MLS for some particular types of clouds.

The data sets give a consistent view of comparably high ice masses above areas of Africa and South America. This in contrast to corresponding ice fields in ECMWF and climate models, as noticed in $\mathrm{Li}$ et al. $(2005,2007)$ and Eriksson et al. (2007a). Figs. 5-7 show that the ice mass over these areas has a clear annual cycle, with minimum during the JJA season and maximum around the DJF season. The analysis in Li et al. (2005) was performed for January 2005, and the noted difference to climate models is probably smaller (in absolute units) for other seasons. A combination of the data sets reveals clear diurnal variations for these areas (Eriksson et al., 2007b), and this can contribute to differences in mean value between SMR and CloudSat/MLS noted below. Diurnal variations are much less pronounced over the oceans.

\subsection{Comparison of mean values}

The match between local mean pIWP values is analysed further in Fig. 8. The spread of the data points is significant for all three instrument pairs, but smallest for the MLS-CloudSat due to the higher statistical noise in the SMR data. Other 

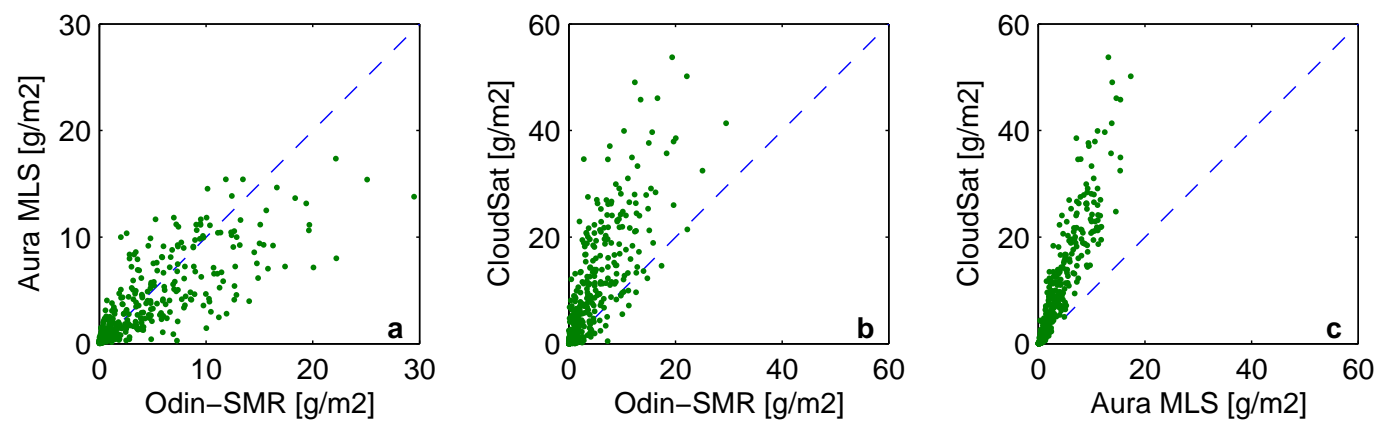

Fig. 8. Comparison of local mean values, between SMR and MLS (a), between SMR and CloudSat (b), and between MLS and CloudSat (c). Same data as in Figs. 5-7, but divided into areas with length of $15^{\circ}$ in both latitude and longitude. The one-to-one relationship is given as a dashed line.

likely contributions to the spread are inter-annual variations of local mean values, and a varying impact of the PSD and beam filling effects. The data are best centred around the 1-1 line for SMR-MLS, while CloudSat gives significantly higher pIWP. The overall mean values are also 3.7, 4.2 and $9.6 \mathrm{~g} \mathrm{~m}^{-2}$ for MLS, SMR and CloudSat, respectively.

CloudSat and MLS IWC values are weighted with the vertical response of SMR to achieve a comparison, and a difference between mean values of SMR and the other instruments can be caused by an incorrect estimation of this response. An alternative evaluation of the vertical response is found in Fig. 1. Application of the alternative response does not change the geographical structure of pIWP fields, but results in an increase of mean values of about $40 \%$, giving overall means of $5.0 / 13.7 \mathrm{~g} \mathrm{~m}^{-2}$ for MLS/CloudSat. This shall be taken as an estimation of the maximum uncertainty caused by this part of the SMR retrievals.

MLS and CloudSat IWC profiles are weighted with same vertical response and the only complication for a comparison between the two instruments is that data are given as a function of pressure and altitude, respectively. Conversion between pressure and altitude should only cause marginal uncertainty. It has been discussed if MLS retrievals overestimate cloud top altitudes by about $1 \mathrm{~km}$ (Wu et al., 2008). This question is not investigated here. It is just noted that a downward shift of the MLS IWC profiles should further increase the difference between MLS and CloudSat.

CloudSat is here found to provide the highest values. This in total contrast to a first version of the paper. That manuscript version was finished before the release of CloudSat R04 and the R03 product was used (together with MLS V1.5). A more detailed analysis of the R03 data revealed that failure in obtaining convergence of the iterative retrieval was closely related to the atmospheric state. This happened predominately in the centre of stronger convective areas and the cases of highest ice mass were missing in the dataset (only tropical latitudes were investigated). Accordingly, the reason for the difference between R03 and R04 seen in Fig. 3 is not only changed retrieval assumptions, but also a more sta- ble retrieval procedure in $\mathrm{R} 04$. The $\mathrm{R} 03$ problems caused a strong underestimation of mean ice mass values (Table 1).

A possible cause for the higher CloudSat R04 mean values is the deviating assumptions on average PSD. The MH97 PSD is assumed for SMR and MLS. CloudSat results when assuming MH97 are found in Table 1 for a single month of data. If the ratio between R04 and MH97 results in Table 1 is assumed to be valid for the complete year, the overall mean for CloudSat using MH97 would be $6.3 \mathrm{~g} \mathrm{~m}^{-2}$. This is in better agreement with overall SMR and MLS means, but is still about $60 \%$ above. If instead LIO0 is applied for CloudSat, the same overall mean as for SMR is obtained $\left(4.2 \mathrm{~g} \mathrm{~m}^{-2}\right)$.

\subsection{Probability density functions}

Deeper insight into the performance of the different retrievals can be obtained by comparing probability density functions (PDFs). That is, the relative occurrence rate of different pIWP values, with respect to the total number of data points. This implies comparison on single measurement basis and some additional effects need to be considered. For example, instrumental noise should have little influence on seasonal means for all three instruments, but will cause differences between the PDFs for lower pIWP. Only values above $4 \mathrm{~g} \mathrm{~m}^{-2}$ are considered for this reason. This corresponds to a relatively safe detection threshold for Odin-SMR. The other instruments are better in this respect.

A more critical consideration is the difference in horizontal resolution. This is illustrated in Fig. 9, where PDFs for CloudSat data averaged over different distances are displayed. The frequency of lower pIWPs increases with the size of averaging window. The reverse impact is found for highest pIWP, showing that such pIWP values are normally confined to smaller areas. This observation is in line with the discussion of the beam filling effect in Sect. 3.2.

PDFs for complete data sets are compared in Fig. 10. The CloudSat averaging length selected for this figure matches the SMR resolution. The MLS PDF is then expected to be somewhat higher below about $600 \mathrm{~g} \mathrm{~m}^{-2}$. Considering this 


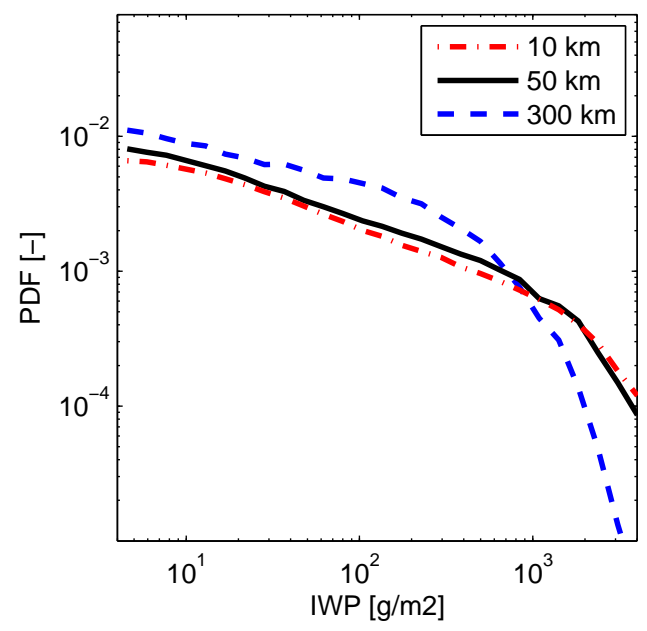

Fig. 9. Distribution of CloudSat pIWP values when averaged over different along-track distances.

expected difference, a general agreement between the PDFs up to about $100 \mathrm{~g} \mathrm{~m}^{-2}$ could be claimed, though the PDFs differ with a factor of 2 . The best consistency with the CloudSat PDF for the highest pIWP range is obtained for SMR, but only if the cloud inhomogeneity correction is applied. Figure 10 could be interpreted as that an even bigger correction of the SMR data should be applied, but the difference could also be explained the deviating PSD assumptions: the CloudSat MH97 PDF is below R04 for higher IWC and altitudes $\geq 12.5 \mathrm{~km}$ (Fig. 3).

The SMR results without cloud inhomogeneity correction reach somewhat higher pIWP than MLS. This is contradictory to the conclusion of a lower impact of beam filling for MLS (Sect. 3.2). On the other hand, MLS has a more rapid transition to saturation. The pIWP column starts at $12 \mathrm{~km}$ (Fig. 1), higher IWC values are found up to about $16 \mathrm{~km}$ (Fig. 3), and the maximum effective cloud height with relevance for pIWP is about $4 \mathrm{~km}$. The combination of a saturation around $0.1 \mathrm{~g} \mathrm{~m}^{-3}$ and a maximum cloud height of $4 \mathrm{~km}$, gives that pIWP values above $\sim 400 \mathrm{~g} \mathrm{~m}^{-2}$ are not expected for MLS.

\section{Summary and conclusions}

Data from early official Odin-SMR (Eriksson et al., 2007a), Aura MLS (V2.2) and CloudSat (2B-CWC-RO, R04) microwave cloud ice retrievals have been compared. The SMR data product is a partial ice column (pIWP), starting at $\approx 12 \mathrm{~km}$, and MLS and CloudSat ice water content profiles are weighted according to Fig. 1 for the comparison. Only latitudes inside $\pm 30^{\circ}$ have been considered.

Geographical regions with very low mean values coincide very well between the instruments, and match the general expectations on areas with a low amount of high clouds. This shows that none of the retrievals suffers of a significant de-

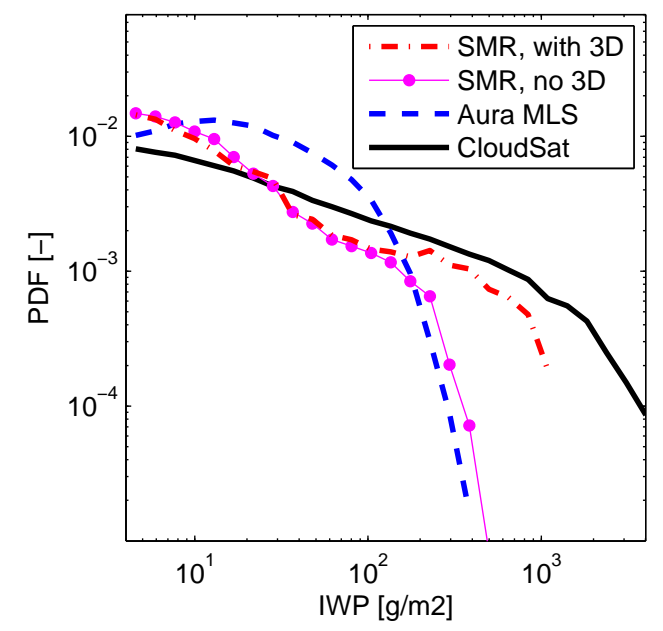

Fig. 10. Distribution of pIWP values for complete Aura MLS, OdinSMR and CloudSat data sets. For Odin-SMR data are shown with and without correction for cloud inhomogeneity. CloudSat data are shown for $50 \mathrm{~km}$ averaging, to roughly match the SMR footprint.

gree of false cloud detections. In addition, all the retrievals have a relatively high dynamic range and a consistent view of the geographical distribution of the cloud ice mass is obtained. However, there are substantial differences in retrieved mean values. CloudSat gives the highest values with an overall mean of $9.6 \mathrm{~g} \mathrm{~m}^{-2}$. The same values for MLS and SMR are 3.7 and $4.2 \mathrm{~g} \mathrm{~m}^{-2}$, respectively.

All the retrievals involve assumptions concerning the particle size distribution (PSD). Microwave techniques are primarily sensitive to the particle fraction having the largest size and the amount of small particles is estimated by an extrapolation of measurement information using the assumed PSD. It is shown that the resulting retrieval uncertainty should be relatively similar for all of the instruments. The PSD of McFarquhar and Heymsfield (1997) (MH97) is applied for both MLS and SMR. Test retrievals for CloudSat based on this PSD gave results with lower averages than the corresponding official data, with IWC differences increasing with altitude $(60 \%$ at $15.5 \mathrm{~km})$. The difference in terms of pIWP was found to be $34 \%$. An even larger decrease in mean pIWP $(56 \%)$ was obtained when applying the dBZ-IWC mapping of Liu and Illingworth (2000). Similar PSD related retrieval uncertainties for MLS and SMR were found in Wu et al. (2008) and Eriksson et al. (2007a).

The poorer spatial resolution of SMR and MLS results in two additional considerations for these instruments. Firstly, inhomogeneities of the ice field over the antenna footprint, combined with a non-linear relationship between ice mass and measured signal, cause a retrieval uncertainty denoted as the beam filling problem. Secondly, the poorer vertical resolution of MLS and SMR gives a possible ambiguity in the altitude of observed cloud ice mass. The maximum error for the latter effect was estimated to $40 \%$ for SMR. 
The demanding task of a complete analysis of the beam filling question must be left for future studies, but CloudSat data have been used here to make a simplistic characterisation for SMR. The possibility of a high systematic retrieval error was verified. The lower and upper limit for the overall SMR mean, just considering this error source, was estimated to 2.3 and $8.9 \mathrm{~g} \mathrm{~m}^{-2}$, respectively. An important conclusion of this comparison is that beam filling most likely causes an underestimation for both MLS and SMR, this despite an already important correction term for SMR. This conclusion is based on the fact that CloudSat retrievals based on MH97 gave results $60 \%$ above MLS and SMR.

Other error sources exist for all three instruments, but have been estimated elsewhere to be less important. For example, the retrieval uncertainty associated with particle shape and orientation has been estimated to $20 \%$ for MLS (Wu et al., 2008), 15\% for SMR (Eriksson et al., 2007a) and 10\% for CloudSat (Benedetti et al., 2003). PSD uncertainties and beam filling are accordingly judged to be the two main causes to differences between the mean values of the instruments. Potential exists for improving the situation concerning beam filling for MLS and SMR, and retrieval enhancements are in progress for both instruments. Decreasing the PSD related errors is less straightforward as this requires external data. A combination of the microwave techniques with simultaneous satellite IR data should be beneficial for the high clouds of concern here, but a clear need exists for improved in situ data.

If the span of values ( 2.3 to $13.7 \mathrm{~g} \mathrm{~m}^{-2}$ ) found is used as a total error estimation, the overall mean pIWP is found to be $8.0 \pm 5.7 \mathrm{~g} \mathrm{~m}^{-2}$. This worst case estimate gives an uncertainty of $71 \%$. As discussed above, the accuracy could be improved considerably by future retrieval versions, but the present retrieval performance is still encouraging considering the high spread of cloud ice masses among climate models (Li et al., 2005; John and Soden, 2006). Already the present datasets should constitute a good validation source for improving the parametrisation of cloud physic processes used in atmospheric models.

Acknowledgements. Financial support was provided by the Swedish Space Board and the Swedish National Graduate school of Space Technology. The Odin cloud ice dataset is based on essential contributions from the Odin-SMR retrieval group and the ARTS community.

\section{Edited by: T. Garrett}

\section{References}

Benedetti, A., Stephens, G. L., and Haynes, J. M.: Ice cloud microphysics retrievals from millimeter radar and visible optical depth using an estimation theory approach, J. Geophys. Res., 108(D11), 4335, doi:10.1029/2002JD002693, 2003.

Buehler, S. A., Jimenez, C., Evans, K. F., Eriksson, P., Rydberg, B., Heymsfield, A. J., Stubenrauch, C., Lohmann, U., Emde, C.,
John, V. O., Sreerekha, T. R., and Davis, C. P.: A concept for a satellite mission to measure cloud ice water path and ice particle size, Q. J. Roy. Meteor. Soc., 133, 109-128, doi:10.1002/qj.143, 2007.

Davis, C. P., Evans, K. F., Buehler, S. A., Wu, D. L., and Pumphrey, H. C.: 3-D polarised simulations of space-borne passive $\mathrm{mm} / \mathrm{sub}-$ mm midlatitude cirrus observations: a case study, Atmos. Chem. Phys., 7, 4149-4158, 2007, http://www.atmos-chem-phys.net/7/4149/2007/.

Dessler, A. E. and Yang, P.: The distribution of tropical thin cirrus clouds inferred from Terra MODIS data, J. Climate, 16, 12411247, 2003.

Donovan, D. P.: Ice-cloud effective particle size parameterization based on combined lidar, radar reflectivity, and mean Doppler velocity measurements, J. Geophys. Res., 108(D18), 4573, doi: 10.1029/2003JD003469, 2003.

Ekström, M., Eriksson, P., Rydberg, B., and Murtagh, D. P.: First Odin sub-mm retrievals in the tropical upper troposphere: humidity and cloud ice signals, Atmos. Chem. Phys., 7, 459-469, 2007, http://www.atmos-chem-phys.net/7/459/2007/.

Eriksson, P., Ekström, M., Rydberg, B., and Murtagh, D. P.: First Odin sub-mm retrievals in the tropical upper troposphere: ice cloud properties, Atmos. Chem. Phys., 7, 471-483, 2007a, http://www.atmos-chem-phys.net/7/471/2007/.

Eriksson, P., Rydberg, B., Ekström, M., and Murtagh, D. P.: Combining Odin-SMR and A-train cloud ice information, in: EarthCARE workshop, ESA/ESTEC, Noordwijk, The Netherlands, 79 May, 2007b.

Evans, K. F. and Stephens, G. L.: Microwave radiative transfer through clouds composed of realistically shaped ice crystals. Part II : Remote sensing of ice clouds, J. Atmos. Sci., 52, 2058-2072, 1995.

Evans, K. F., Walter, S. J., Heymsfield, A. J., and Deeter, M. N.: Modeling of submillimeter passive remote sensing of cirrus clouds, J. Appl. Meteorol., 37, 184-205, 1998.

Evans, K. F., Walter, S. J., Heymsfield, A. J., and McFarquhar, G. M.: Submillimeter-wave cloud ice radiometer: Simulations of retrieval algorithm performance, J. Geophys. Res., 107, 2.12.21, 2002.

Garrett, T. J., Gerber, H., Baumgardner, D. G., Twohy, C. H., and Weinstock, E. M.: Small, highly reflective ice crystals in low-latitude cirrus, Geophys. Res. Lett., 30, 2132, doi:10.1029/ 2003GL018153, 2003.

Heymsfield, A. J.: On measurements of small ice particles in clouds, Geophys. Res. Lett., 34, L23812, doi:10.1029/ 2007GL030951, 2007.

Heymsfield, A. J. and McFarquhar, G. M.: Cirrus, chap. Midlatitude and tropical cirrus: microphysical properties, Oxford University Press, Inc., New York, 78-101, 2002.

Hong, G., Heygster, G., Miao, J., and Kunzi, K.: Detection of tropical deep convective clouds from AMSU-B water vapor channels measurements, J. Geophys. Res., 110, D05205, doi: 10.1029/2004JD004949, 2005.

Jarnot, R. F., Perun, V. S., and Schwartz, M. J.: Radiometric and spectral performance and calibration of the $\mathrm{GHz}$ bands of EOS MLS, IEEE Trans. Geosci. Remote Sensing, 44, 1131-1143, 2006.

John, V. O. and Soden, B. J.: Does convectively-detrained cloud 
ice enhance water vapor feedback?, Geophys. Res. Lett., 33, L20701, doi:10.1029/2006GL027260, 2006.

Li, J. L., Waliser, D. E., Jiang, J., Wu, D. L., Read, W., Waters, J. W., Tompkins, A. M., Donner, L. J., Chern, J. D., Tao, W. K., Atlas, R., Gu, Y., Liou, K. N., Genio, A. D., Khairoutdinov, M., and Gettelman, A.: Comparisons of EOS MLS cloud ice measurements with ECMWF analyses and GCM simulations: Initial results, Geophys. Res. Lett., 32, L18710, doi: 10.1029/2005GL023788, 2005.

Li, J. L., Jiang, J., Waliser, D. E., and Tompkins, A. M.: Assessing consistency between EOS MLS and ECMWF analyzed and forecast estimates of cloud ice, Geophys. Res. Lett., 34, L08701, doi:10.1029/2006GL029022, 2007.

Liu, C. L. and Illingworth, A.: Toward more accurate retrievals of ice water content from radar measurements of clouds, J. Appl. Meteorol., 30, 1130-1146, 2000.

McFarquhar, G. M. and Heymsfield, A. J.: Parameterization of tropical cirrus ice crystal size distribution and implications for radiative transfer: Results from CEPEX, J. Atmos. Sci., 54, 21872200, 1997.

Murtagh, D., Frisk, U., Merino, F., Ridal, M., Jonsson, A., Stegman, J., Witt, G., Eriksson, P., Jiménez, C., Megie, G., de La Noë, J., Ricaud, P., Baron, P., Pardo, J. R., Hauchcorne, A., Llewellyn, E. J., Degenstein, D. A., Gattinger, R. L., Lloyd, N. D., Evans, W. F. J., McDade, I. C., Haley, C., Sioris, C., von Savigny, C., Solheim, B. H., McConnell, J. C., Strong, K., Richardson, E. H., Leppelmeier, G. W., Kyrölä, E., Auvinen, H., and Oikarinen, L.: An overview of the Odin atmospheric mission, Can. J. Phys., 80, 309-319, 2002.

Stephens, G. L., Vane, D. G., Boain, R. J., Mace, G. G., Sassen, K., Wang, Z. E., Illingworth, A. J., O'Connor, E. J., Rossow, W. B., Durden, S. L., Miller, S., Austin, R. T., Benedetti, A., and Mitrescu, C.: The CloudSat mission and the A-train - A new dimension of space-based observations of clouds and precipitation, B. Am. Meteorol. Soc., 83, 1771-1790, 2002.
Su, H., Read, W. G., Jiang, J. H., Waters, J. W., Wu, D. L., and Fetzer, E. J.: Enhanced positive water vapor feedback associated with tropical deep convection: New evidence from Aura MLS, Geophys. Res. Lett., 33, L05709, doi:10.1029/2005GL025505, 2006a.

Su, H., Waliser, D. E., Jiang, J. H., Li, J. L., Read, W. G., Waters, J. W., and Tompkins, A. M.: Relationships of upper tropospheric water vapor, clouds and SST: MLS observations, ECMWF analyses and GCM simulations, Geophys. Res. Lett., 33, L22802, doi:10.1029/2006GL027582, 2006b.

Waters, J. W., Froidevaux, L., Harwood, R. S., Jarnot, R. F., Pickett, H. M., Read, W., Siegel, P. H., Cofield, R. E., Filipiak, M. J., Flower, D. A., Holden, J. R., Lau, G. K., Livesey, N. J., Manney, G. L., Pumphrey, H. C., Santee, M. L., Wu, W. L., Cuddy, D. T., Lay, R. R., Loo, M. S., Perun, V. S., Schwartz, M. J., Stek, P., Thurstans, R. P., Boyles, M. A., Chandra, K. M., Chavez, M. C., Chen, G. S., Chudasama, B. V., Dodge, R., Fuller, R. A., Girard, M. A., Jiang, J. H., Jiang, Y. B., Knosp, B. W., LaBelle, R., Lam, J. C., Lee, K. A., Miller, D., Oswald, J. E., Patel, N. C., Pukala, D. M., Quintero, O., Scaff, D. M., Snyder, W. V., Tope, M. C., Wagner, P., and Walch, M.: The Earth Observing System Microwave Limb Sounder (EOS MLS) on the Aura satellite, IEEE Trans. Geosci. Remote Sensing, 44, 1075-1092, 2006.

Wu, D. L., Read, W. G., Dessler, A. E., Sherwood, S. C., and Jiang, J. H.: UARS/MLS cloud ice measurements: Implications for $\mathrm{H}_{2} \mathrm{O}$ transport near the tropopause, J. Atmos. Sci., 62, 518-530, 2005.

Wu, D. L., Jiang, J. H., and Davis, C. P.: EOS MLS cloud ice measurements and cloudy-sky radiative transfer model, IEEE Trans. Geosci. Remote Sensing, 44, 1156-1165, 2006.

Wu, D. L., Jiang, J. H., Read, W. G., Austin, R. T., Davis, C. P., Lambert, A., Kahn, B. H., Nankervis, C. J., Sneep, M., Veefkind, J. P., Pumphrey, H. C., Stephens, G. L., Tanelli, S., Vane, D. G., and Waters, J. W.: Validation of Aura MLS cloud ice water conent (IWC) measurements, J. Geophys. Res., in press, 2008. 